\title{
Textualidad mediática y realidad aumentada en Los muertos de Jorge Carrión
}

\author{
JULIETA MARINA VANNEY Universidad de Buenos Aires, Argentina / julietavanney@gmail.com
}

\section{Resumen}

La incorporación de formas novedosas de las nuevas tecnologías a la práctica literaria produce nuevos tipos de textos y nuevas formas de aproximación a la lectura. Así, se entiende a la literatura como algo más que puro lenguaje en su aproximación al mundo de los medios masivos de comunicación. En la novela Los muertos de Jorge Carrión se incorporan diversos elementos que se hacen eco de los modelos estructurales y modos de representación de los medios de comunicación de masas como parte constitutiva del texto. Sin embargo, el texto no se queda en la mera incorporación de medios tecnológicos al entramado literario, en un intento por generar un efecto de contemporaneidad. Nos proponemos analizar la forma en que este trabajo con la textualidad mediática resulta ser una estrategia para reflexionar sobre el vínculo que se establece entre ficción y realidad. Este hecho da lugar al abordaje de una propuesta sobre el lugar que podría ocupar la literatura en el panorama tecnológico actual.

Palabras clave: medios de comunicación / transmedialidad / fragmentariedad / virtualidad / realidad aumentada

\section{Media textuality and augmented reality in Los muertos of Jorge Carrión}

\section{Abstract}

The incorporation of novel forms of new technologies into literary practice produces new types of texts and new ways of approaching reading. Thus, literature is understood as something more than pure language in its approach to the world of mass media. In the novel Los muertos by Jorge Carrión, various elements that reflect the structural models and modes of representation of the mass media as a constituent part of the text are incorporated. However, the text does not stop at the mere incorporation of technological means into the literary framework, in an attempt to generate a contemporaneous effect. We propose to analyze the way in which this work with the media textuality turns out to be a strategy to reflect on the link that is established between fiction and reality. This fact gives rise to the approach of a proposal on the place that literature could occupy in the current technological landscape.

Key words: mass media / transmediality / fragmentariness / virtuality / augmented reality

Recibido: 26/06/2019. Aceptado: 24/07/2019

Para citar este artículo: Vanney, J.M. (2019). Textualidad mediática y realidad aumentada en Los muertos de Jorge Carrión. El taco en la brea, 10 (junio-noviembre), 47-56. Santa Fe, Argentina: UNL. DOI: 10.14409/ tb.v1i10.8684 
Agustín Fernández Mallo sostiene en Postpoesía que el arte se ha convertido en la actualidad en un instrumento privilegiado del presente y de la simultaneidad. Las obras de arte, «han sido superadas en muchos órdenes de magnitud por la gigantesca obra de arte que hoy es la vida, con sus relaciones, sus flujos, su ficción, su uso» (69). Cabe preguntarse, entonces, cuál es el lugar que ocupa la literatura y de qué manera convive con la realidad multimediática actual. En el libro Afterpop. La literatura de la implosión mediática, Eloy Fernández Porta presenta una nueva concepción estética y cultural para comprender la literatura contemporánea. En este sentido, afirma que la cultura pop ha muerto y utiliza el término «afterpop» para designar aquellos fenómenos culturales posteriores a la cultura pop.' La frontera entre lo que se considera alta cultura y cultura popular se desdibuja, permitiendo así la incorporación de elementos de los medios masivos de comunicación dentro del entramado de los textos literarios. Se trata, en otras palabras, de señalar un nuevo campo de referencias para la literatura, ya no solo determinado por el sentido de los textos sino también por la confluencia de diferentes medios tales como la imagen, el sonido, las redes, etc. En este sentido, sostiene Fernández Porta:

Las aproximaciones literarias al paisaje mediático consideran no solo la presencia literal del lenguaje, oral o escrito, en la infosfera, sino, más allá, los presupuestos que la constituyen, entendidos como presupuestos específicamente discursivos. Hablar en términos de textualidad mediática implica superar la concepción puramente literata de la escritura para asumir otras modalidades de expresión que configuran el estilo de la época. (63)

Los textos a los que se hace referencia en la cita se presentan como experimentos literarios que entienden a la literatura como algo más que puro lenguaje en su aproximación al mundo de los medios masivos de comunicación. El hecho de incorporar de formas novedosas las nuevas tecnologías a la práctica literaria produce entonces nuevos tipos de textos y nuevas formas de aproximación a la lectura.

En este contexto debe entenderse el surgimiento de una nueva generación de autores que presentan planteos novedosos en torno a la concepción de la literatura contemporánea. Se considera como punto de referencia para este grupo la publicación de la novela Nocilla dream (2006) de Agustín Fernández Mallo (hecho que, además, les dio el nombre: generación Nocilla). Entre las principales características del grupo nos encontramos con una marcada influencia de los medios de comunicación de masas y una adopción, en sus obras, de modelos estructurales propios de las nuevas tecnologías. Jorge Carrión afirma que, dentro de las características del grupo, se encuentra el hecho de compartir «un horizonte televisivo, iconos pop, una cierta forma de vivir la sentimentalidad, la frecuentación de países e idiomas, una formación académica interdisciplinar, etc.» (Azancot, 2007). Este hecho, señala, convive con una crítica al poder de la imagen y de los medios. La influencia de internet dentro de este grupo es evidente y se encuentra presente tanto en las temáticas que abordan sus textos como en las técnicas de escritura de las que hacen uso.

Salta fácilmente a la vista el hecho de que en la novela Los muertos de Jorge Carrión se incorporan diversos elementos que se hacen eco de los modelos estructurales y modos de representación de los medios de comunicación de masas como parte constitutiva del texto. Tal como afirma Vicente Luis Mora en un artículo sobre la trilogía de Jorge Carrión: 
comentando la estructura de Los muertos, escribí: «existen por tanto hasta cuatro ficciones superpuestas: 1) Los muertos (la serie), 2) las vidas o ficciones anteriores de las que provienen los personajes de la serie, 3) Los muertos (la novela) y 4) otra novela apócrifa, Los muertos. La novela oficial, apuntada en el ensayo final y que habría sido encargada por los productores a una tal Martha H. de Santis, y de la que se reproduce un extracto». Hoy diría lo mismo de una forma mucho más sintética y precisa: Los muertos es la descripción de un transmedia inventado. (2015)

Sin embargo, el texto no se detiene en la incorporación de referencias tecnológicas al entramado literario con el objetivo de generar un efecto de contemporaneidad. Nos proponemos analizar la forma en que este trabajo con la textualidad mediática resulta ser una estrategia de la que el texto se sirve para reflexionar sobre el vínculo que se establece entre ficción y realidad en un mundo en el que, como afirma Fernández Mallo, la vida, saturada de ficción, se vuelve una obra de arte. De esta manera, en Los muertos se nos presenta una ficción televisiva que invade el entramado de la realidad y modifica el vínculo de los seres humanos con su propia historia y con las producciones artísticas. Asimismo, este hecho da lugar al abordaje de una propuesta sobre el lugar que podría ocupar la literatura en el panorama tecnológico actual: un nuevo tipo de realismo que, en lugar de reproducir la realidad a partir de sus acontecimientos más relevantes, se propone reelaborar el entramado de lo real a partir de los mismos mecanismos por los cuales este se construye: la fragmentariedad, la virtualidad y los medios masivos de comunicación. La propuesta consiste, entonces, en realizar un trabajo con las mediaciones tecnológicas sin dejar de sostener la distancia y la tensión existente entre el espacio mediático y la literatura. En este sentido, Los muertos se construye como un texto literario que, en términos de Josefina Ludmer, «construye presente», es decir, sale de la literatura y se mete en lo cotidiano, dibujando los límites entre la ficción y la realidad. En última instancia, podemos afirmar que estamos frente a un texto que se inspira en el mundo del mercado para devolverle al lector una imagen extrañada del mismo.

\section{Literatura e imagen: la página y la pantalla}

Vicente Luis Mora señala que en la actualidad se produce un deslizamiento: la literatura incorpora la imagen como una nueva serie de sentido: «la literatura es productora de un inconsciente que, a su vez, está construido como un lenguaje; pero debemos entender que lenguaje supone "una acepción más amplia que la de lengua"» (2012:46). Las obras literarias pueden estar compuestas por elementos no específicamente textuales, incorporando lo visual y ampliando el formato «textovisual» de las mismas, es decir, aquel que «conjuga texto e imagen en lo horizontal y una continuidad de artes, ciencias y tecnologías en su semántica vertical» (109). Ante esta conjugación de texto e imagen en la literatura cabe preguntarse, entonces, de qué manera la literatura «ve». En el caso de Los muertos, señala Mora, el ojo del narrador tradicional se encuentra disuelto en otras formas narrativas: la serie televisiva y el artículo científico. Es decir, no hay una voz que sostenga la narración a lo largo del texto. Los dos artículos nos explican las repercusiones y el alcance de la serie de televisión. En el caso de la serie, tenemos acceso a un texto que no es más que la descripción de lo que aparentemente podría verse en la pantalla a partir de una voz narrativa que, a su vez, realiza intervenciones o apreciaciones sobre el material narrado, por ejemplo: «La ciudad parece más virtual que nunca, más maqueta. Pura irrealidad metropolitana» (Carrión:121), señala quien narra. 
$\mathrm{Al}$ incorporar la imagen televisiva al discurso literario, se desdobla la función del lector, que se convierte, en términos de Mora, en un lectoespectador, es decir, aquel que es receptor de una forma artística compuesta por texto más imagen. Por este motivo, en el acto de leer, el lector está comprendiendo la estructura de la serie que se nos presenta como si la estuviese viendo en una pantalla. Por lo tanto, las palabras no están ahí para transformar la imagen en literatura, para reemplazarla, sino para recrearla desde el lenguaje literario, para generar una experiencia televisiva desde la página del libro. En este sentido, la página, como la pantalla, se vuelve un elemento diseñable, porque incorpora una «imagen construida, temporal o dinámica, proveniente de los medios de comunicación de masas» (Mora, 2012:77).

\section{El lenguaje de la pantalla}

La movilidad de las cámaras y la agilidad narrativa de las películas y series han colaborado a lo largo del tiempo a construir una forma de percibir que se ha vuelto fragmentaria (Mora, 2012). Desde la literatura, los mismos escritores se encuentran influenciados por el sistema visual televisivo y se hacen eco de estas modificaciones en la percepción al incorporarlas a la escritura.

Una de las innovaciones formales que resalta en Los muertos consiste en la incorporación de un texto que reproduce la estructura de una serie televisiva homónima alrededor de la cual gira la novela: se trata de dos temporadas divididas en ocho capítulos respectivamente y, en cada uno de ellos, cada párrafo representa una escena. Este hecho incrementa la fragmentariedad de la narración, así como su velocidad y simultaneidad, permitiendo recrear la experiencia del espectador televisivo desde las páginas del libro; a modo de ejemplo: «El Nuevo duerme. Roy se cruza (sin reconocimiento) con el hombre que le contaba su sueño de destrucción al psicoanalista. El Nuevo duerme. Roy camina e interroga periódicamente “¿Ha visto a este hombre?” El Nuevo duerme. Roy insiste. El Nuevo duerme» (Carrión:19). A su vez, en cada capítulo de la serie «Los muertos» nos encontramos con descripciones de este estilo: «En la pantalla, un cuerpo desnudo recibe agresiones conocidas, inscrito en el aura vibrátil de un charco» (14) o «el Nuevo cierra los ojos y gime, como si llorara» (23). Con estas indicaciones, la serie hace referencia a un tipo de símbolos o de gestos fácilmente reconocibles por parte de aquellos que son consumidores de productos audiovisuales: cuando se mencionan las «agresiones conocidas» y la vibración del charco simboliza un modo estereotipado de ejercer violencia presente en las series, una imagen frecuente que funciona de la misma forma que otras: por ejemplo, cerrar los ojos y gemir resulta equivalente al llanto. Es decir, a partir de estas referencias se evoca una suerte de lenguaje universal dentro de la economía narrativa de la industria del entretenimiento, de manera que aquel que lee puede hacerse una imagen mental del tipo de golpes o el tipo de llanto que están siendo representados en la pantalla porque ya lo ha visto muchas veces con anterioridad. En este sentido, también hay un uso particular del castellano que se evidencia, a modo de ejemplo, cuando Selena interrumpe a Nadia con un «Calla, puta» (65) en el episodio final de la primera temporada. La variedad de castellano que leemos en los diálogos de la serie parece corresponderse con la estructura de la traducción literal del inglés, hecho que da como resultado estructuras sintácticas no comunes en castellano (como la antes citada) pero frecuentes en el inglés coloquial tales como «shut up bitch». Aunque exigiría una demostración más cuidadosa, podríamos pensar que los diálogos que leemos en el texto se corresponden con lo que serían los subtítulos o un doblaje literal de una serie que originalmente se encuentra en idioma inglés. Los procedimientos mencionados hacen referencia a un espacio 
ficcional genérico, globalizado, que se reconstruye en el texto literario al presentar una serie localizada en la ciudad de Nueva York, pero no pensada como un espacio físico real sino, tal como afirma Mora: «en una Norteamérica ficticia e ideal, proveniente de la imagen de los medios de comunicación y, en consecuencia, distorsionada» (Mora, 2006).

En Los muertos se realiza entonces un doble movimiento. En un primer momento se incorporan los elementos y lenguajes de los medios masivos de comunicación a la literatura recuperando, de esta manera, la modalidad de experiencia del espectador multimediático y del imaginario tecnológico contemporáneo. Sin embargo, este hecho da lugar a un segundo movimiento en el que la escritura deforma lo que puede ser la simple incorporación de esta economía de la comunicación televisiva. En otras palabras, en Los muertos se apela a una economía narrativa típica de la industria del entretenimiento que pone en evidencia la construcción de un tipo de mirada y, de ese modo, desautomatiza la percepción del lector acostumbrado a la pantalla televisiva. La serie, en su pasaje a la escritura, abandona su estatuto televisivo y pasa a ser una reflexión sobre los medios que la componen y el modo en que se la consume. Si pensamos que la trasposición de un texto literario a la pantalla presupone siempre una lectura condicionada por aquel que lo ha adaptado al medio audiovisual, lo mismo debemos suponer en el caso opuesto: la traducción de una serie al lenguaje literario (aunque esta serie no tenga existencia real) también consiste en una trasposición de la inmediatez de sus medios a las mediaciones de la práctica literaria. Tal como menciona Mora, haciendo referencia a una reflexión de Fernández Mallo:

antes el flujo energético era: desde la intimidad del autor (su erudición y sus psique, mito romántico) a la exterioridad de los lectores y la sociedad (la información). (...) Y hoy el flujo sería en cierto modo inverso: desde la exterioridad de la información (publicidad, red, cine, etc.) a la interioridad del autor, que rehace a su antojo toda esa información que después devuelve transformada. (Mora:19)

Podemos pensar, entonces, que el proceso de creación se inicia con una inspiración en el formato de la serie televisiva pero culmina en la reelaboración que rearma y resignifica esos materiales con un medio que les es extraño, el literario.

\section{La novela y la serie}

Hacia el final de la novela, el lector resulta descolocado cuando el último de los artículos impugna el estatuto de texto literario de la serie que estuvimos leyendo: «Insistimos: una transformación de Los muertos al lenguaje literario es sencillamente imposible» (Carrión:162). Este hecho llama la atención sobre el vacío existente entre el texto que estamos leyendo (las dos temporadas de «Los muertos») y la serie de la que se habla (la serie real, a la que no tenemos acceso). Dicho artículo se cierra con un fragmento de la novela basada en la serie, encargada por los productores a una tal Marta De Santis. Este cierre intenta demostrar por elocuencia y contraste por qué la novela no funciona y por qué resulta necesario recurrir a otros medios que no son los tradicionales para reproducir, desde la práctica literaria, una ficción de estas características. El motivo principal es, como se afirma en el artículo, que los lectores de la novela fueron previamente televidentes. Hay, por lo tanto, dos versiones del final de la serie televisiva. La siguiente es la versión que leemos en la escena final del último capítulo de la segunda temporada: 
En las pantallas que estudia el Topo ya no hay presencia humana. Cada televisor etiquetado («Londres», «París», «Berlín», «Jerusalén», «Pekín», «Tokio», «Los Ángeles», «Nueva York») retransmite un fragmento de una desaparición que se sabe global, absoluta. Ya no llegan faxes. Sólo circula la información que no precisa de intervención humana. (Carrión:113)

Y esta es su equivalente en la novela de De Santis:

Picado: en las pantallas que estudia Bruce ya no hay presencia humana. Su rostro se refleja en ellas. Cada televisor retransmite una imagen posible de desolación global. En la pantalla de Londres se ve un callejón cercano a Trafalgar Square completamente vacío de humanidad; en la de París, un hotel inerte de la periferia, e cuya fachada alguien ha reproducido un cuadro de Chagall (...) Un zoom permite observar la mirada de Bruce: quizá excitada pero definitivamente no horrorizada. Otro zoom: sigue hablándole al micrófono. (Carrión:163)

Un simple contraste entre los dos fragmentos pone en evidencia que la escena, efectiva en el primer caso, se desdibuja, en cambio, en el segundo, debido a las innumerables descripciones que intentan, con exceso, reponer la ausencia del soporte televisivo como elemento condensador de significado. La incorporación de términos como «picado» 0 «zoom» intenta compensar la ausencia de la cámara en la narración, pero resultan forzados dentro de la misma. Por este motivo, la novela solo puede caer en el fracaso, en la acumulación de materiales. Se hace énfasis, en numerosos momentos, en el hecho de que la novela no puede reponer con el lenguaje aquello que tenía efecto en el formato serie, ya que dicha estructura resulta intraducible al lenguaje literario (tradicional, al menos). En el segundo de los artículos se afirma:

Ellos no quisieron escribir una novela, cuyo alcance en la conciencia global a estas alturas de la segunda década del siglo XXI sería muy limitado; ellos quisieron —y lograron — elevar el arte televisivo, auténticamente influyente y determinante de nuestra época, a un nivel que nadie hubiera pensado que era posible (...) en esa tensión entre palabra e imagen quizá radique el enigma del arte. Nosotros hemos intentado acercarnos a una traducción que solo puede ser puro deseo. (163)

Hacia el final del fragmento citado se menciona un intento de traducción de la serie. Este hecho funciona como clave de lectura y como una respuesta a la cuestión del estatuto del texto que estuvimos leyendo durante la primera y la segunda temporada de "Los muertos»: la serie que hemos leído no es la versión «literaria» sino la traducción al lenguaje literario de la misma; una traducción que, como tal, conserva algo de los dos órdenes de sentido que se encuentran en juego y, en este caso, mantiene la tensión entre la palabra y la imagen sin resolverla. En este sentido, Jorge Carrión señala en una entrevista que Los muertos es una novela que reivindica lo audiovisual porque se trata de una serie, escrita con palabras y sin incorporar imágenes fotográficas, ya que introducirlas le parecía que era contradecir al proyecto. Es decir, nos encontramos frente a una traducción de aquello que se ve en la pantalla, que no puede ser más que un deseo y que se lleva a cabo trabajando sobre la distancia constitutiva de los órdenes que la componen. Las dos temporadas de "Los muertos» a las que tenemos acceso deberían ser pensadas, entonces. a partir del concepto de «realidad aumentada» que introduce Mora como un procedimiento que trabaja con la 
incorporación de las nuevas tecnologías a la narración y que consiste en un «modo técnico de relación con el lector (interface literaria) que provoca que el efecto de lectura lleve a una percepción "visual" de una realidad superior a la que produce la narración convencional» (Mora, 2006:1). De manera que resulta deliberado el abandono de las formas tradicionales de la narración en busca de nuevas formas de narrar que, a partir de la incorporación de elementos del imaginario tecnológico y mediático, permitan aumentar la percepción visual del material narrado en busca de un perfeccionamiento de la idea de realidad en el texto literario logrado a partir de la incorporación a la escritura de procedimientos experimentales como los señalados anteriormente.

\section{Ficción y realidad}

A partir del trabajo con la textualidad mediática el texto Los muertos se instala en una realidad cotidiana para fabricar presente (Ludmer): en el texto se nos presenta una serie exitosa, un público para esa serie, una entrevista a sus creadores en un conocido show nocturno, una plataforma virtual creada a partir de la misma y sus repercusiones sociales y culturales. Se trata de hechos y acontecimientos que fácilmente podrían tener lugar en el mundo actual. Los muertos podría ubicarse dentro de una serie de textos que

\footnotetext{
Salen de la literatura y entran a «la realidad» y a lo cotidiano, a la realidad de lo cotidiano, y lo cotidiano es la TV y los medios, los blogs, el e-mail, Internet. Fabrican presente con la realidad cotidiana y esa es una de sus políticas. La realidad cotidiana no es la realidad histórica referencial y verosímil del pensamiento realista y de su historia política y social (la realidad separada de la ficción), sino una realidad producida y construida por los medios, las tecnologías y las ciencias. (Ludmer:151)
}

Es por eso que esta novela se instala en la ambivalencia: es ficción, pero, al mismo tiempo, realidad. Carrión se hace eco de las técnicas de las que hacen uso los medios masivos de comunicación para la creación de una realidad verosímil y le presenta al lector la información en los mismos soportes en los que éste recibe el resto de la información diaria (Mora, 2012). En este sentido, Josefina Ludmer señala que el escritor contemporáneo reacciona ante la civilización audiovisual, ante la disolución de las fronteras entre realidad y representación, y que esto da como resultado el hecho de pensar la realidad como un simulacro. ${ }^{2}$ Es por eso que este trabajo con la textualidad mediática que se lleva a cabo en la novela da lugar a una reflexión alrededor del lugar de la literatura en una realidad como la actual, que no necesita ser representada porque ya es pura representación. Por este motivo, el vínculo entre ficción y realidad se encuentra indagado en el texto tanto a partir del argumento de la serie como también a partir de las repercusiones de la misma en la realidad de la que forma parte.

La primera articulación entre ficción y realidad la encontramos tematizada en la serie «Los muertos», donde los personajes son de ficción pero están inmersos en un mundo que no la conoce porque en la TV solo se proyectan noticieros y documentales. Esta construcción de un mundo carente de ficción evidencia, justamente por su ausencia, que todo el resto del entramado de la realidad es ficcional. Es por este motivo que el arco temporal elegido para la misma (1995-2015) es importante en relación con el desarrollo de los medios y de internet como constructores de realidades alrededor del mundo. Tanto la identidad, en la primera temporada, como el poder, en la segunda, se construyen sobre la base de una ficción. En la primera temporada el conflicto se centra alrededor de los personajes que necesitan saber quiénes son y a qué comunidad pertenecen; tal 
como afirma «el Nuevo» al leer en su diario íntimo: «Es curioso cómo algo tan arbitrario como un nombre nos ayuda a confiar en nosotros mismos; tener un nombre significa poseernos. Aunque sea una ficción (otro día hablaré aquí de esa compleja palabra)» (Carrión:37). El acto de nominación resulta ser un acontecimiento fundamental para los personajes ya que les permite reconstruir un pasado y les da la posibilidad de sumarse a una comunidad determinada y actuar en el presente. Luego, ya en la segunda temporada, nos encontramos con la posibilidad de que los personajes se inventen un pasado, se creen una identidad a la fuerza. Incluso la invención de una identidad se configura como una forma de constituir el liderazgo dentro de una comunidad determinada, tal como ejemplifica el caso de los múltiples Tony Soprano.

A su vez, tal como se menciona en el segundo artículo, la ficción televisiva "Los muertos» se ubica dentro de una serie de ficciones («Expedientes $\mathrm{X} » \mathrm{y}$ «Twin Peaks») que se han ocupado de indagar sobre la muerte en relación con el límite de lo humano, la noción de comunidad y las masacres de las que ha sido testigo la humanidad a lo largo del siglo XX y en los comienzos del XXI. Al parecer, «Los muertos» representa un intento de hablar del genocidio desde la serialidad televisiva, pero no desde la perspectiva de aquellos que lo han sufrido, sino de una generación posterior a aquella, que puede mantener una mirada distanciada, irónica, con respecto a dichos acontecimientos: «Se conoce como "narrativa postraumática" al conjunto de relatos que ha querido dar cuenta de la experiencia del límite, a menudo vinculada con el mundo concentracionario, cuando no con el de la tortura o la violencia institucional, creados por la generación posterior a la que sufrió esa experiencia» (Carrión:154). Jorge Carrión afirma en una entrevista que la novela Los muertos se vincula con la cultura del rescate y con una nueva conciencia que adquiere la humanidad sobre los muertos de la ficción. Este hecho es el que permite, en última instancia, llevar a la conciencia el duelo por las masacres sufridas por la humanidad:

en una sociedad constituida exclusivamente por los muertos de la ficción, sin lazos bidireccionales con la realidad de procedencia, vacía de victimarios, los responsables últimos de las masacres cuyas consecuencias estamos tratando de imaginar en el televisor (o en otras pantallas) éramos nosotros, espectadores. (Carrión:156)

Tal como se afirma en el texto, esta injerencia de la ficción en la realidad se produce con el objetivo de dar un primer paso hacia el camino del duelo, de la catarsis, y para preservar un tipo de memoria y responsabilidad de la que no se tenía conciencia. En este sentido, sostiene Mora que:

el sujeto «postraumático» es uno de los más comunes de nuestro tiempo, frustrado por traumas violentos que le superan (...), hechos imborrables como los que han podido ocasionar el 11/S, Fukushima, los tsunamis, los terremotos, el terrorismo, etc. Zizek y Malabou se mantienen en el estudio del trauma, mientras Carrión intenta ir más allá y entiende que la ficción es uno de los medios de terapia de grupo. (Mora, 2015:3)

En el texto de Carrión nos encontramos entonces con una segunda articulación de la dicotomía realidad/ficción: la serie (es decir: aquel mundo ficcional donde no existe la ficción) invade la realidad y produce modificaciones en el mundo del que forma parte. En el artículo «Nuestro dolor» el escritor afirma:

nunca la humanidad ha vertebrado un discurso sistemático sobre la desaparición simbólica, es decir, que siempre ha reflexionado sobre cómo el símbolo, la metáfora, la literatura, traducen fenómenos reales (...), 
pero nunca se ha tratado, ni siquiera de forma indirecta, cómo la muerte concreta de un personaje textual o ficticio puede provocar dolor, no individual, sino colectivo. (Carrión:76)

En Los muertos en lugar de buscar qué es lo que dice la ficción acerca de la realidad, nos encontramos con la situación inversa: de qué manera una ficción puede generar efectos concretos en la realidad, cómo puede crear su propio entramado dentro la misma y modificar las relaciones de los seres humanos entre sí y, a su vez, de los seres humanos con las producciones artísticas. El primer artículo habla de los efectos de la serie en la realidad: los productos que derivan de la misma y los duelos que genera en función de la toma de conciencia sobre los muertos de la ficción. El sitio web mypain hace realidad la premisa de la serie: las personas pueden vincularse con los personajes que han muerto en la ficción. Como se afirma en el artículo, el mundo presentado por mypain no tiene que ver con la serie pero surge de esta y abre, al mismo tiempo, infinitas posibilidades de desarrollo argumental gestionadas por usuarios que se proponen darle una segunda oportunidad a las víctimas de la ficción humana. Este fenómeno, se remarca, genera una nueva forma de diálogo en el mundo y una nueva clase de intercambio cultural entre las personas. Así, es la realidad la que interpela al universo literario y no viceversa: «este boom de la ficcionalidad ha revitalizado la literatura, porque ha creado un interés renovado por la lectura, la investigación y la reflexión acerca del universo literario» (Carrión:81). En consecuencia, el universo de la ficción se entreteje con el mundo «real» y produce, de esa forma, una modificación en el mismo.

Podemos afirmar que Los muertos de Jorge Carrión es un texto que no copia la realidad a partir de sus acontecimientos más relevantes sino que trabaja con los medios de los que se vale la misma para crear el entramado que la compone. Así, Los muertos se aleja de un tipo de novela tradicional al presentar una serie de materiales sin el "pegamento» (en términos de Mora) que supondría su pasaje a la forma novelística: las temporadas de la serie, los artículos científicos, la entrevista a los creadores. En efecto, no encontramos en el texto una historia central, un conflicto y sus personajes, sino, en cambio, el relato de una experiencia fragmentaria producto del imaginario tecnológico contemporáneo o, en otras palabras, un transmedia inventado. ${ }^{3}$ El fragmentarismo presente en la novela podría pensarse como un nuevo tipo de realismo porque da como resultado una literatura que sirve para contar su tiempo, que se vincula de manera más adecuada con la realidad de la que forma parte. En este sentido, Vicente Luis Mora afirma:

los autores mutantes han conseguido observar su tiempo y asumir su epistemología, sus medios, su ciencia, su sociología, y aplicarla en las novelas. Miran compleja y ambiciosamente el mundo y crean mecanismos (cada autor uno distinto) para reproducirla. Y sí, precisamente porque nuestra realidad es inaprensible y no puede verse de un vistazo, la narrativa fragmentaria es la única que puede reproducir nuestra percepción, con lo cual es la más realista, la más exacta. (Azancot, 2010:3)

Los muertos propone, entonces, la construcción de una nueva clase de realismo, un «realismo aumentado", que no sólo incorpore las mediaciones tecnológicas contemporáneas sino que también pueda crear su propio entramado real, que pueda interferir en el mundo como la serie «Los muertos» lo ha hecho. Es decir, trabajando con los materiales y los conflictos de la realidad de un modo no mimético. En el mundo contemporáneo, sostiene Carrión, es a través de lo virtual que hemos aprendido a comunicarnos con la realidad circundante. En este mundo regido por la virtualidad, 
un texto literario experimental, que incluye el formato de una serie televisiva inventada, así como también las repercusiones de la misma en los medios de comunicación y las redes sociales recuperadas desde el artículo científico, se vuelve realista por más extraña que parezca la propuesta.

\section{Notas}

$1 \mathrm{El}$ autor afterpop asume que la cultura de consumo tal y como se conoció a lo largo de la segunda mitad del siglo XX está en ruinas y representa un pasado inmediato. La posición de este tipo de narradores se describe como una secuencia de interferencias, dimisiones, reentradas y refutaciones que suceden después (históricamente, discursivamente, emocionalmente) de la cultura pop tradicional. Fernández Porta menciona, entre los textos más significativos de esta corriente, La fiesta del asno de Juan Francisco Ferre, Proust Fiction de Robert Juan-Cantavella, El vano ayer de Isaac Rosa, Unas vacaciones baratas en la miseria de los demás de Julián Rodríguez. Se trata de obras que implican una reconsideración de la herencia textual desde la actualidad de la imagen, sea en formato televisivo, fotográfico, cinematográfico o de las artes en general (Fernández Porta).

2 El planteo de Ludmer se deriva, naturalmente, de la filosofía Jean Baudrillard. Para el francés el «simulacro» supone una lógica representativa que no puede homologarse a una simple imitación o recreación de la realidad, sino lo contrario: manifiesta el fin de toda imitación y la destrucción de cualquier referencia, y la búsqueda de otra noción de semejanza no platónica. Así las cosas, esta «fase» del arte y del mundo, es lo que Baudrillard llama «transestética» (58).

$3 \mathrm{El}$ primero en hablar de narrativa trasmedia fue Henry Jenkis al hacer referencia a aquellas historias que se cuentan a través de diversos medios. Por su parte, Carlos Scolari define este tipo de narrativa como la combinación de dos elementos: por un lado, una historia se expande en muchos medios y plataformas (ya sea comic, películas, videojuegos, novelas) y cada uno de esos textos cuenta una parte diferente de dicho mundo narrativo; por otro lado, los fans o usuarios también participan en la expansión del relato, y lo hacen a través de parodias, de la creación de finales alternativos o nuevos personajes, o bien expandiendo las experiencias de los personajes propios del relato (Scolari).

\section{Referencias bibliográficas}

Azancot, N. (2007). La generación Nocilla y el afterpop piden paso. El cultural, suplemento de El mundo. http:// www.elcultural.es/version_papel/LETRAS/21006/La_generacion_Nocilla_y_el_afterpop_piden_paso/ (2010). Los fragmentarios, ¿a muerte con los clásicos? El cultural, suplemento de El mundo. http://www.elcultural.es/version_papel/LETRAS/26783/Los_fragmentarios_a_muerte_con_los_clasicos

Baudrillard, J. (1997). La ilusión y la desilusión estéticas. Caracas: Sala Mebdosza.

Carrión, J. (2010). Los muertos. Barcelona: Mondadori.

Fernández Mallo, A. (2009). Postpoesía. Hacia un nuevo paradigma. (selección). Barcelona: Anagrama.

Fernández Porta, E. (2010). Arferpop. La literatura de la implosión mediática. Barcelona: Anagrama.

García Tirado, S. Jorge Carrión. La memoria histórica del futuro. Blisstopic. http://www.blisstopic.com/ index.php/libros/entrevistas/item/2752-jorge-carrion-entrevista/2752-jorge-carrion-entrevista

Mora, V.L. (2012). El lectoespectador. Barcelona: Seix Barral.

(2006). El realismo aumentado. Quimera, (276). http://www.candaya.com/nocillaquimeranov.pdf (2015). Acercamiento a la trilogía de Jorge Carrión. En Diario de lecturas. Blog.

Ludmer, J. (2010). Identidades territoriales y fabricación de presente. En Aquí América Latina. Una especulación. Buenos Aires: Eterna Cadencia, 149-178.

Scolari, C. (2013). Narrativas transmedia. Cuando todos los medios cuentan. Barcelona: Planeta. 